(2rossMark

Cite this: RSC Adv., 2016, 6, 33510

\section{Two-photon FRET pairs based on coumarin and DBD dyes $\uparrow$}

\author{
P. Wessig, ${ }^{\star}$ N. Behrends, M. U. Kumke, U. Eisold, T. Meiling and C. Hille
}

Received 13th February 2016

Accepted 27th March 2016

DOI: 10.1039/c6ra03983a

www.rsc.org/advances

The synthesis and photophysical properties of two new FRET pairs based on coumarin as a donor and DBD dye as an acceptor are described. The introduction of a bromo atom dramatically increases the two-photon excitation (2PE) cross section providing a 2PE-FRET system, which is also suitable for 2PE-FLIM.

Amongst various analytical techniques, the evaluation of fluorescence signals is one of the most sensitive methods. ${ }^{1}$ Therefore, fluorescence spectroscopy has found a wide range of applications in biology, biochemistry, and clinical diagnostics. Besides classic steady state measurements that evaluate the fluorescence intensity, methods utilizing the fluorescence lifetime have gained growing interest in recent years. Both parameters are successfully applied in fluorescence imaging. The pivotal element of these methods is the fluorescent dye and its properties. Small fluorescent organic molecules play, beside quantum dots (QD) ${ }^{2}$ and luminescent lanthanide complexes, ${ }^{3}$ the central role in current fluorescence spectroscopy. The potential of a fluorescent dye is determined by the combination of its photophysical parameters, such as fluorescence quantum yield $\left(\Phi_{\mathrm{F}}\right)$, molar extinction coefficient $(\varepsilon)$, fluorescence lifetime $\left(\tau_{\mathrm{F}}\right)$, absorption and emission wavelength $\left(\lambda_{\mathrm{ABS}}, \lambda_{\mathrm{EM}}\right)$, and stability against photobleaching. Because the penetration depth of light in biological tissue is increased with increasing wavelength, high $\lambda_{\mathrm{ABS}}$ and $\lambda_{\mathrm{EM}}$ are desirable. However, a longwavelength absorption maximum is usually connected with low thermal and photochemical stability of the dyes. This problem can be circumvented by two-photon excitation (2PE), ${ }^{4}$ which is based on the simultaneous absorption of two photons with lower energy instead of one photon with high energy. Consequently, the excitation wavelength $\lambda_{\text {ExC }}$ is almost doubled in $2 \mathrm{PE}$. The probability of the $2 \mathrm{PE}$ is described by its $2 \mathrm{PE}$ cross

Institut für Chemie, Universität Potsdam, Karl-Liebknecht-Str. 24-25, 14476 Potsdam, Germany. E-mail: wessig@uni-potsdam.de; Fax: +49-331977-5065; Tel: +49-3319775401

$\dagger$ Electronic supplementary information (ESI) available. See DOI: 10.1039/c6ra03983a section $\sigma_{2}$. Unfortunately, $\sigma_{2}$ is low for most organic molecules. ${ }^{5}$ On the other hand the applicability of many fluorescence dyes suitable for $2 \mathrm{PE}$ is limited when considering the other photophysical properties. The combination of the outstanding properties of two fluorescent dyes within one molecule can be achieved by a pair of dyes capable for Förster Resonance Energy Transfer (FRET). ${ }^{6}$ This phenomenon, in which one dye (the donor D) is excited and the energy is transferred to the other dye (the acceptor $\mathrm{A}$ ), is observed if the emission spectrum of $\mathrm{D}$ and the absorption spectrum of A sufficiently overlap. Furthermore, the FRET efficiency is strongly distance-dependent (the distance with $50 \%$ FRET efficiency is called Förster distance $R_{0}$ ) and is influenced by the relative arrangement of the transition dipole moments of D and A. A special type of FRET exists if the donor D is capable of $2 \mathrm{PE}$. In this case, the fluorescence of the donor $\mathrm{D}$ as well as the acceptor A can be observed at shorter wavelength than the excitation ("Anti-Stokes shift"). Although some

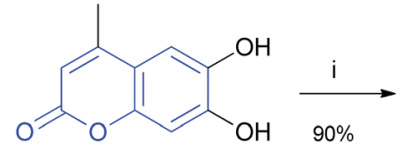

1
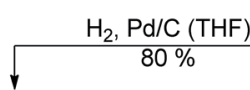<smiles>Cc1cc(=O)oc2cc3c(cc12)OC(CC(=O)O)O3</smiles>

$3 a$<smiles>Cc1cc(=O)oc2cc3c(cc12)OC(CC(=O)OCc1ccccc1)O3</smiles>

2

NBS, NaOAc (ACN) $100 \%$<smiles>Cc1c(Br)c(=O)oc2cc3c(cc12)OC(CC(=O)OCc1ccccc1)O3</smiles>

4<smiles>Cc1c(Br)c(=O)oc2cc3c(cc12)OC(CC(=O)O)O3</smiles>

Scheme 1 Synthesis of coumarins 3a,b (i benzyl prop-2-ynoate, DMAP) 


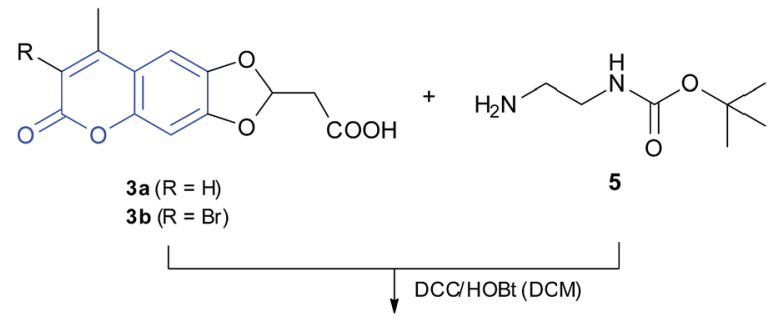<smiles>[R]c1c(C)c2cc3c(cc2oc1=O)OC(CC(=O)NCCNC(=O)OC(C)(C)C)O3</smiles>

6a $90 \%$<smiles>[R]c1c(C)c2cc3c(cc2oc1=O)OC(CC(=O)NCC[18OH])O3</smiles>

Scheme 2 Synthesis of compounds $7 a, b$.

examples of 2PE-FRET pairs were reported in the literature, ${ }^{7}$ the number of 2PE-FRET systems is rather limited.

In the last few years, we have developed a new class of fluorescent dyes, whose structure is based on $[1,3]$ dioxolo[ $[4,5-$ $f][1,3]$ benzo-dioxole (DBD).$^{8-14}$ These dyes are characterised by large Stokes shifts $\left(\Delta \lambda=\lambda_{\mathrm{EM}}-\lambda_{\mathrm{ABS}}>100 \mathrm{~nm}\right)$, combined with long fluorescent lifetimes $\left(\tau_{\mathrm{F}}>20 \mathrm{~ns}\right)$ and exceptional bleaching stability. The 2PE cross-sections $\sigma_{2}$ of DBD dyes are, however, rather low (vide infra). Recently, we reported on a first FRET pair with DBD dyes as acceptor and 2,5-diphenyloxazol (PPO) as donor. ${ }^{13}$ Herein we wish to report on the synthesis and properties of new FRET pairs with coumarin derivatives as donor and DBD dyes as acceptor for 2PE-FRET application.<smiles>CCCC(=O)c1c2c(c(C(=O)CCC)c3c1OC(C(=O)O)O3)OC(CC(=O)O)O2</smiles>

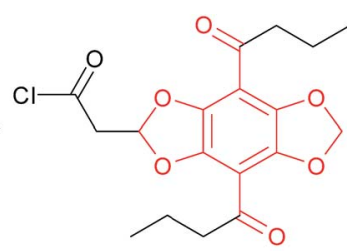

9<smiles>[R]c1c(C)c2cc3c(cc2oc1=O)OC(CC(=O)NCCNC(=O)CC1Oc2c(c(C(=O)CCC)c4c(c2C(=O)CCC)OCO4)O1)O3</smiles>

$10 \mathrm{a}(\mathrm{R}=\mathrm{H}) \quad 94 \%$

$10 \mathrm{~b}(\mathrm{R}=\mathrm{Br}) 90 \%$
Table 1 Summary of spectroscopic data of compounds 2, 4, 8, 10a, and 10b (DMSO)

\begin{tabular}{lllllll}
\hline Compound & $\lambda_{\mathrm{ABS}} / \mathrm{nm}$ & $\lambda_{\mathrm{EM}} / \mathrm{nm}$ & $\tau_{\mathrm{F}} / \mathrm{ns}$ & $\varepsilon / \mathrm{M}^{-1} \mathrm{~cm}^{-1}$ & $\Phi_{\mathrm{F}}$ & $\sigma_{2} / \mathrm{GM}^{a}$ \\
\hline $\mathbf{2}$ & 343 & 413 & $0.8^{b}$ & 10878 & 0.23 & $0.01 \pm 17 \%$ \\
$\mathbf{4}$ & 353 & 436 & $1.3^{b}$ & 15269 & 0.17 & $13.86 \pm 4 \%$ \\
$\mathbf{8}$ & 437 & 570 & $24.8^{c}$ & 3094 & 0.68 & $0.04 \pm 3 \%$ \\
$\mathbf{1 0 a}$ & 344,433 & 570 & $24.0^{d}-$ & - & - \\
$\mathbf{1 0 b}$ & 355,434 & 570 & $23.5^{d}-$ & - & - \\
\\
\end{tabular}

The coumarin chromophore was chosen because it is already known to be suitable for $2 \mathrm{PE} .{ }^{15}$ The synthesis starts with the commercially available 6,7-dihydroxy-coumarin 1 . The reaction with benzyl prop-2-ynoate ${ }^{16}$ in the presence of catalytical amounts of DMAP afforded coumarin 2 with very good yield.

This type of cyclisation has already been described for other catechols ${ }^{\mathbf{8}, 10,17}$ but never applied to coumarins. Because the introduction of halogen atoms regularly increases the $2 \mathrm{PE}$ crosssection, 2 was brominated with NBS to give 3-bromo-coumarin in quantitative yield. Subsequently, esters $\mathbf{2}$ and $\mathbf{4}$ were deprotected by catalytic hydrogenation to the carboxylic acids $\mathbf{3 a}, \mathbf{b}$ (Scheme 1 ). The connection between coumarin and DBD chromophore was accomplished by a 1,2-diaminoethane linker. For this purpose, esters $\mathbf{3 a}, \mathbf{b}$ were converted into amides $\mathbf{6 a}, \mathbf{b}$ by reaction with commercially available $N$-Boc-1,2-diaminoethane 5 , which were subsequently deprotected to give primary amines 7 (Scheme 2).

Finally, the FRET pairs 10a,b were prepared from amines 7a,b and acyl chloride 9, which is easily accessible from the known DBD acid 8 (Scheme 3). ${ }^{10}$
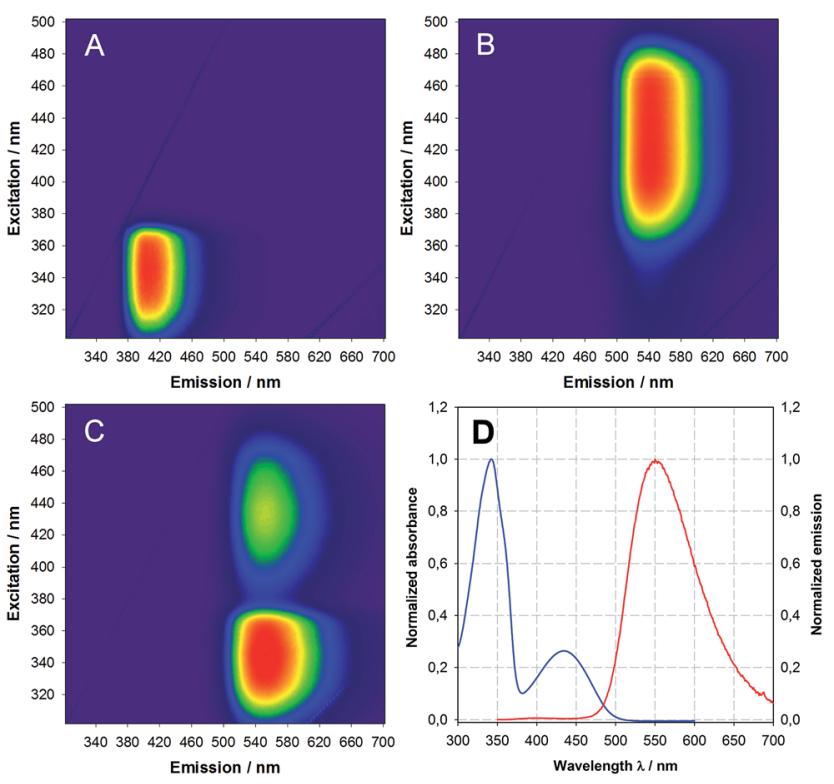

Fig. 1 3D excitation emission matrix (EEM) of (A) coumarin 2, (B) DBD 8, (C) FRET pair 10a and (D) absorption (blue) and emission (red) spectra of FRET pair 10a in DCM (excitation at $340 \mathrm{~nm}$ ). 

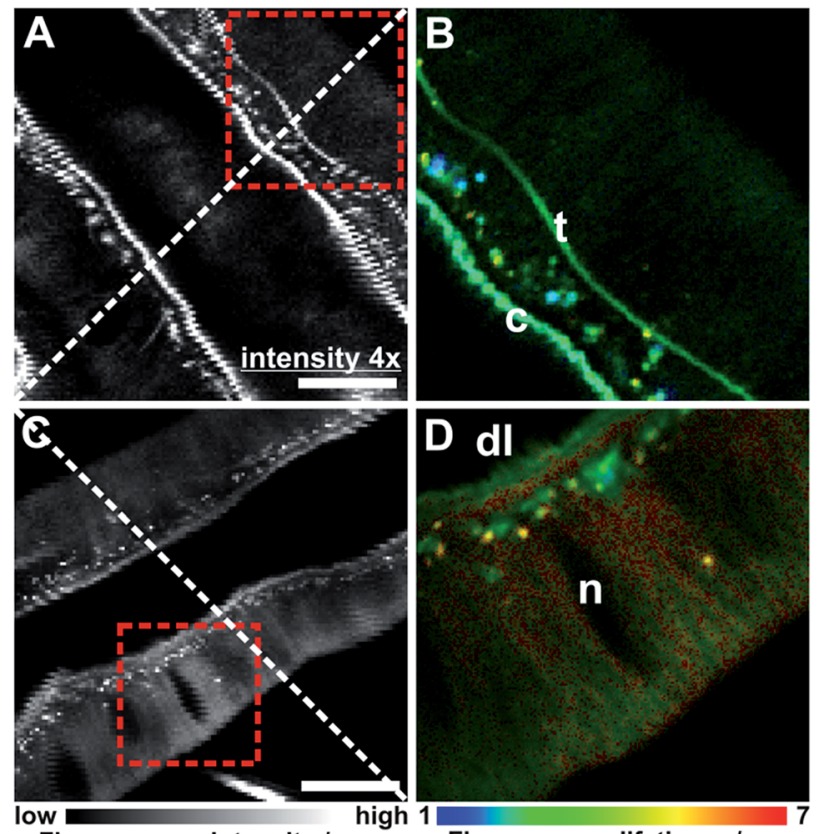

Fluorescence intensity / a.u.

Fluorescence lifetime $\tau / \mathrm{ns}$
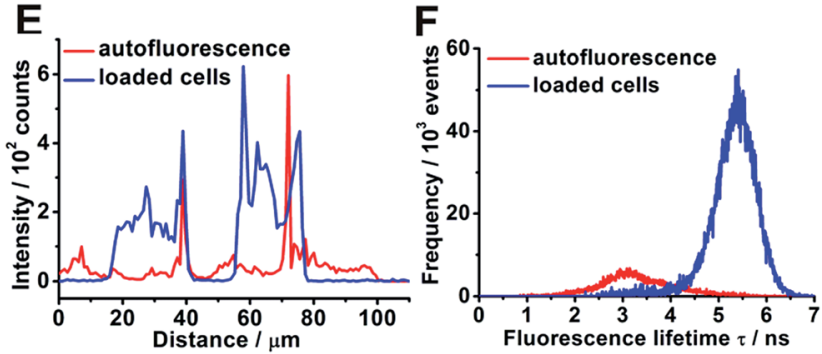

Fig. 2 Autofluorescence intensity image of a salivary duct $\times 4$ boosted for visibility $(A)$ and corresponding $2 \mathrm{PE}-$ FLIM image of the red rectangle (B). Fluorescence intensity image of $10 \mathrm{~b}$-loaded salivary duct (C) and corresponding 2PE-FLIM image of the red rectangle (D). Scale bar $=20 \mu \mathrm{m} ; \mathrm{c}=$ luminal cuticule; $\mathrm{t}=$ trachea; $\mathrm{dl}=$ duct lumen; $\mathrm{n}=$ nucleus. (E) Intensity profiles along the dashed lines in (A) and (C). (F) Fluorescence lifetime histograms for the 2PE-FLIM images shown in (B) and (D).

Next, we investigated the spectroscopic properties of compounds 10a,b in comparison with the starting compounds 2, 4, 8. The results in DMSO are summarized in Table 1 (for other solvents see ESI†). Of particular note are the large Stokes shift $(133 \mathrm{~nm})$ and the long fluorescence lifetime $(24.8 \mathrm{~ns})$ of DBD dye 8 compared with coumarins 2 and 4 . The successful FRET in compound 10a,b was shown by 3D-fluorescence experiments, which are exemplarily outlined for 10a in Fig. 1.

The highly efficient FRET in compound 10a is stressed in Fig. 1C by (i) the strong quenching of the donor emission (compare to Fig. 1A) and (ii) the strong emission of the DBD acceptor under indirect excitation via the coumarin donor (compare to Fig. 1B). This result was to be expected, because the maximum possible distance between the chromophores (1.5$1.6 \mathrm{~nm}$ ) is markedly below the Förster radius $R_{0}$ for this FRET pair $(2.56 \mathrm{~nm}$, for details see the ESI $\dagger$ ).

Whereas the $2 \mathrm{PE}$ cross section $\sigma_{2}$ is very low for $\mathrm{DBD}$ compound $\mathbf{8}$ and coumarin $\mathbf{2}$, the introduction of bromine in coumarin 4 significantly enhances the $\sigma_{2}$ value to $0.74 \mathrm{GM}$ (see Table 1).

In order to explore potential applications of the 2PE-FRET pairs-sensor 10b in living cells, its uptake into such was studied in 2PE-fluorescence lifetime imaging (2PE-FLIM) experiments. Insect salivary gland lobes were incubated for $15 \mathrm{~min}$ with $2 \mu \mathrm{M}$ 10b and then, the tubular-like salivary ducts were imaged. Salivary ducts without 10b-loading displayed a comparatively low autofluorescence when excited at $780 \mathrm{~nm}$ as expected for 2PE (Fig. 2A and E). ${ }^{18}$ Mainly the luminal cuticule and tracheae contributed to the autofluorescence (Fig. 2B) and the corresponding fluorescence lifetime distribution fluctuated around $3 \mathrm{~ns}$ (Fig. 2F). In contrast, the fluorescence intensity of 10b-loaded salivary ducts was up to one order of magnitude higher than that of unloaded ducts (Fig. 2C and E). Such a loading efficiency has previously been reported for other ionsensitive fluorescent dyes. ${ }^{19}$ Here, the duct cells were stained strongly and 10b did not accumulate in specific cellular compartments. However, almost no fluorescence could be observed in the nuclei and the duct lumen (Fig. 2D). This result is a prerequisite for successful intracellular recordings using the novel 2PE-FRET pairs presented. The sufficient 10b-loading into living cells could also be observed in the fluorescence lifetime distribution, which was now shifted to longer lifetimes around 5.5 ns (Fig. 2F).

\section{Conclusions}

Both single chromophores exhibit specific pros and cons. The 3bromocoumarin shows a sufficiently large $2 \mathrm{PE}$ cross section ( $0.74 \mathrm{GM})$ but has a low fluorescence lifetime (1.3 ns) and a relatively short emission wavelength $(436 \mathrm{~nm})$.

By contrast, the DBD chromophore shows long emission wavelength $(570 \mathrm{~nm})$, large fluorescence lifetime $(23-25 \mathrm{~ns})$ but very low $2 \mathrm{PE}$ cross section. The FRET pair 10b perfectly combines the advantages of these dyes. After long-wavelength two-photon excitation at $780 \mathrm{~nm}$ an efficient FRET takes place resulting in a long-lived emission at $570 \mathrm{~nm}$. The applicability of 10b for 2PE-FLIM was demonstrated with the aid of living cells of insect salivary gland lobes. In this application the large contrast range of 1-7 ns is noteworthy. Currently, we are investigating synthetic routes to derivatives of $\mathbf{1 0 b}$, which are suitable for coupling with various biomolecules.

\section{Notes and references}

$1 \mathrm{~J}$. R. Lakowicz, Principles of Fluorescence Spectroscopy, Springer, 3rd edn, 2006.

2 D. Bera, L. Qian, T.-K. Tseng and P. H. Holloway, Materials, 2010, 3, 2260.

3 S. Faulkner, S. J. A. Pope and B. P. Burton-Pye, Appl. Spectrosc. Rev., 2005, 40, 1.

4 (a) M. Goeppert-Mayer, Ann. Phys., 1931, 9, 273; (b) B. Valeur, M. N. Berberan-Santos, Molecular Fluorescence, Wiley-VCH, 2nd edn, 2013; (c) J. S. Park, J.-K. Park, P. Prabhakaran and K.-S. Lee, Nonlinear Opt., Quantum Opt., 2015, 46, 227. 
5 N. S. Makarov, M. Drobizhev and A. Rebane, Opt. Express, 2008, 16, 4029.

6 (a) B. Valeur, M. Berberan-Santos, Molecular Fluorescence: Principles and Applications, Wiley-VCH, Weinheim, 2nd edn, 2012, pp. 213-261; (b) C. G. dos Remedios and P. D. J. Moens, J. Struct. Biol., 1995, 115, 175.

7 (a) M. Elangovan, H. Wallrabe, Y. Chen, R. N. Day, M. Barroso and A. Periasamy, Methods, 2003, 29, 58; (b) L. Liu, G. Wei, Z. Liu, Z. He, S. Xiao and Q. Wang, Bioconjugate Chem., 2008, 19, 574; (c) L. Liu, H. Li, T. Qiu, G. Zhou, K.-Y. Wong, Z. He and Z. Liu, Chem. Commun., 2011, 47, 2622.

8 P. Wessig, R. Wawrzinek, K. Möllnitz, E. Feldbusch and U. Schilde, Tetrahedron Lett., 2011, 52, 6192.

9 R. Wawrzinek, P. Wessig, K. Möllnitz, J. Nikolaus, R. Schwarzer, P. Müller and A. Herrmann, Bioorg. Med. Chem. Lett., 2012, 5367.

10 R. Wawrzinek, J. Ziomkowska, J. Heuveling, M. Mertens, A. Herrmann, E. Schneider and P. Wessig, Chem.-Eur. J., 2013, 19, 17349.

11 J. Heuveling, V. Frochaux, J. Ziomkowska, R. Wawrzinek, P. Wessig, A. Herrmann and E. Schneider, Biochim. Biophys. Acta, Biomembr., 2014, 1838, 106.
12 C. Meyners, R. Wawrzinek, A. Krämer, S. Hinz, P. Wessig and F.-J. Meyer-Almes, Anal. Bioanal. Chem., 2014, 4889.

13 R. Wawrzinek and P. Wessig, Dyes Pigm., 2015, 123, 39.

14 D. Bader, D. T. Klier, C. Hettrich, F. F. Bier and P. Wessig, Anal. Methods, 2016, 9, 1235.

15 (a) T. Furuta, S. S.-H. Wang, J. L. Dantzker, T. M. Dore, W. J. Bybee, E. M. Calaway, W. Denk and R. Y. Tsien, Proc. Natl. Acad. Sci. U. S. A., 1999, 96, 1193; (b) N. S. Makarov, M. Drobishev and A. Rebane, Opt. Express, 2008, 16, 4029.

16 Y. C. Fan and O. Kwon, Org. Lett., 2012, 14, 3264.

17 (a) X. Ariza, O. Pineda, J. Vilarrasa, G. W. Shipps Jr., Y. Ma and X. Dai, Org. Lett., 2001, 3, 1399; (b) I. Yavari, L. Azad and T. Sanaeishoar, Monatsh. Chem., 2011, 142, 643; (c) I. Yavari, S. Souri, M. Sirouspour and H. Djahaniani, Synthesis, 2006, 19, 3243; (d) C. Chalumeau, D. Deffieux, S. Chaignepain and S. Quideau, ChemBioChem, 2011, 12, 1193; (e) C. Fu, W. Chen, Y. L. Quek, R. Ni, A. B. A. Ghani, W. W. Y. Leong, H. Zeng and D. Huang, Tetrahedron Lett., 2010, 51, 6322.

18 M. Lahn, C. Dosche and C. Hille, Am. J. Physiol.: Cell Physiol., 2011, 300, C1323.

19 (a) K. Sagolla, H.-G. Löhmannsröben and C. Hille, Anal. Bioanal. Chem., 2013, 405, 8525; (b) K. Jahn and C. Hille, PLoS One, 2014, 9, e105334. 